\title{
Distribution Network Reconfiguration for Power Loss Minimization Using Bacterial Foraging Optimization Algorithm
}

\author{
Manju Mam ${ }^{a^{*}}$, Leena ${ }^{a}{ }^{\text {a }}$ N.S. Saxena ${ }^{b}$ \\ ${ }^{a}$ Manju Mam, Research Scholar, EEE Dept, Faculty of Engineering and Technology, Manav Rachna \\ International University, Faridabad, India \\ ${ }^{a}$ Leena G., Professor, EEE Dept, Faculty of Engineering and Technology, Manav Rachna International \\ University, Faridabad, India \\ ${ }^{b}$ N.S. Saxena, MDI, Operations Faculty Member, Gurgoan, Haryana, India
}

\begin{abstract}
This paper presents a distribution network reconfiguration based on bacterial foraging optimization algorithm (BFOA) along with backward-forward sweep (BFS) load flow method and geographical information system (GIS). Distribution network reconfiguration (DNR) is a complex, non-linear, combinatorial, and nondifferentiable constrained optimization process aimed at finding the radial structure that minimized network power loss while satisfying all operating constraints. BFOA is used to obtain the optimal switching configuration which results in a minimum loss, BFS is used to optimize the deviation in node voltages, and GIS is used for planning and easy analysis purposes. Simulation is performed on the 33-bus system and results are compared with the other approaches. The obtained results show that the proposed approach is better in terms of efficiency and having good convergence criteria.
\end{abstract}

Index Terms: Feeder reconfiguration, Bacterial foraging optimization, Backward-Forward sweep, Power loss reduction, Radial network, Distribution system, Geographical information system

(C) 2016 Published by MECS Publisher. Selection and/or peer review under responsibility of the Research Association of Modern Education and Computer Science.

\section{Introduction}

Electric distribution systems are designed radially for effective coordination between feeder's protection systems and to lower the short circuit currents. The distribution feeders have two types of switches: normally closed (sectionalizing) switches and normally opened (tie) switches ([1]; [2]; [3]; [4]; [5]; [6]; [7]). The major concern for distribution utilities is to reduce the power losses in distribution network [8]. Distribution network reconfiguration (DNR) is the most economical method to reduce the power losses in distribution network [9].

\footnotetext{
* Corresponding author.

E-mail address: manjumam@yahoo.com, leenag.fet@mriu.edu.in,nssaxena@yahoo.co.in
} 
DNR is a process of altering the topological structure of feeders by changing the switching states of normally closed (sectionalizing) switches and normally opened (tie) switches ([10]; [11]). These switching operations must be performed in such a way that resulting network is radial and meets all constraints. With the advancement in computer and automation industry like Geographical Information System (GIS), DNR is being used as a planning and real-time control tool. Regular modification in radial structure of the distribution network is performed, to transfer the loads from one feeder of distribution network to another feeder, in order to improve the operation conditions of overall network and reduce the line losses. Since the daily load variations on each feeder in a distribution network is unpredictable due to mixture of residential, industrial and commercial types of loads.

Loss and reliability are two significant points among several factors in distribution network [12]. Hence feeder reconfiguration helps to transfer the loads from heavily loaded feeders to lightly loaded feeders [10]. These alterations not only reduces the real power losses of the network but also balances the loads among feeders and significantly improves the voltage profiles.

In recent years extensive research has been conducted for power loss minimization in the field of distribution network reconfiguration. Merlin and Back [13] first proposed the distribution network reconfiguration for loss reduction. The method begins with all branches closed to form a meshed network and then procedure of opening the switches is followed to maintain radiality of the network. Shirmohammadi and Hong [14] proposed a heuristic method based on Merlin and Back [13] .The method also starts with all branches closed to form a meshed network and opening of the switch is performed after optimal power flow pattern. The switch having lowest current value for the optimal power flow pattern will be consider first and so on. Many evolutionary and biologically inspired algorithm are presented with time to reduce the losses. Nara et. al [15] proposed Genetic Algorithm (GA) to reduce the network losses using string as a set of switch status, fitness function and penalty factor to limit the voltage and current. Later the approach used by Nara et. al [15] was modified by Zhu et. al [16] by using refined genetic algorithm (RGA). RGA is achieved with some improvements in chromosome coding, fitness function and mutation pattern. Simulated Annealing (SA) method was also proposed by many authors ([17]; [18]) to mitigate the power losses in distribution network reconfiguration. Das et. al [19] uses the concept of heuristic rule and fuzzy multi-objective approach to optimize the network. Although some of these methods are suitable for smaller systems, some have bad convergence property and some are very time consuming due to the use of rigorous mathematics.

In 2012 Kumar and Jayabarathi [20] proposed a method of loss minimization for distribution system reconfiguration using bacterial foraging optimization algorithm (BFOA). The major drawbacks of this methodology are:

- Criteria for selecting switches is not provided

- Newton-Raphson Method is used for load flow analysis (while conventional Gauss-Seidel and NewtonRaphson methods of load flow gives unreliable solutions in distribution network due to radial structure of the network, and has high R/X ratio ([8]; [14]; [16]; [21])

- With the opening of $13^{\text {th }}$ and $14^{\text {th }}$ switches, the load at bus 14 goes out of service, which violates the constraint of distribution network reconfiguration, that no load can be out of service

In this paper BFOA is proposed along with backward-forward sweep (BFS) load flow method and GIS for the minimization of power loss using DNR. The results obtained are very encouraging when proposed algorithm is tested on 33 bus system and BFOA is proven to be an efficient method for distribution network.

The structure of the paper is organized as follows: Section 2 presents the problem formulation. Section 3 provides the necessary details about the backward-forward sweep load flow method. Description of bacterial foraging optimization algorithm is given in Section 4. While Section 5 deals with the implementation of the bacterial foraging optimization. Section 6 presents results of 33-bus system and provides the necessary discussion. The conclusion is outlined in Section 7. 


\section{Problem Formulation}

The problem of distributed network reconfiguration is to find best configuration of radial network having minimum power losses, and meet all operating constraints, which are voltage profile of the network, current capacity of the feeder and radial structure of the distribution network. Since many switching combinations are possible in a distribution network, finding the best configuration is a complex, non-linear, combinatorial, and non-differentiable constrained optimization problem. The objective function for power loss minimization is:

$$
\begin{aligned}
& \text { Minimize } f(x)=\operatorname{Min}\left(P_{T, \text { Loss }}\right) \\
& x=\left[S_{O 1} S_{O 2} S_{O 3} S_{O 4} S_{O 5}\right] \\
& P_{T, \text { Loss }}=\sum_{k=1}^{N b r} P_{\text {Loss }}(k, k+1)
\end{aligned}
$$

where $P_{\text {Loss }}(k, k+1)=R_{k} \times \frac{\left(P_{k}^{2}+Q^{\prime 2}{ }_{k}^{2}\right)}{\left|V_{k}\right|^{2}}$

Subjected to $V_{\min } \leq\left|V_{k}\right| \leq V_{\max }$

and

$$
\left|I_{k}\right| \leq\left|I_{k, \max }\right|
$$

Constraints are:

- No feeder section can be out of service

- Network must be radial

○ $\operatorname{det}(M)=1$ or -1 for radial network

○ $\operatorname{det}(M)=0$ for non-radial network

Where,

$P_{T, \text { Loss }}:$ Total real power loss of the system

$x$ : Control variable representing open switches vector

$R_{k}$ : Resistance of $\mathrm{k}^{\text {th }}$ branch

$P_{k}$ : Real power flowing out of bus $\mathrm{k}$

$Q_{k}$ : Reactive power flowing out of bus k

$\left|I_{k}\right|$ : Current magnitude at $\mathrm{k}^{\text {th }}$ branch

$N b r$ : Total number of branches with respect to $\mathrm{x}$

$S_{\text {On }}: n=1,2,3,4,5$ representing the open switches

$f(x)$ : Total real power loss of the network with respect to $x$

$\left|V_{k}\right|$ : Voltage magnitude at $\mathrm{k}^{\text {th }}$ bus

$V_{\text {min }}$ : Bus minimum voltage limit $\left(V_{\min }=0.9\right.$ p.u $)$

$V_{\text {max }}$ : Bus maximum voltage limit $\left(V_{\max }=1.05\right.$ p.u $)$

$\left|I_{k, \max }\right|$ : Maximum current magnitude at $\mathrm{k}^{\text {th }}$ branch

$M$ : Bus incidence matrix 
The differences in power losses, and voltage drops can be measured from the simulation of the network using power flow before and after the network reconfiguration. Conventional Gauss-Seidel and NewtonRaphson methods of load flow gives unreliable solutions in distribution network due to radial structure of the network, and have high R/X ratio ([8]; [14]; [16]; [21]). Therefore a BFS load flow method is used in this paper. The BF sweep load flow is explained by Ehsan and Javad [22]. A brief description of BF sweep [8] is described in section 3.

\section{Backward-Forward Sweep Load Flow Method}

In order to evaluate the objective function of the problem a BFS load flow method is used. The first step of BFS uses graph theory to convert the topological structure of the distribution network into meaningful matrices [Ehsan and Javad]. Later steps are as follows:

- The vector $V_{k}$ containing the nodes voltages is defined. At first all elements of vector is assigned a value 1 pu or 1.05 pu with zero angle. Where $k \in[1, \mathrm{Nbr}]$ with respect to the control variable $x$.

- The current at each nodes $I_{k}$ is calculated by the following equation:

$$
I_{L}(i)=\left[\frac{P_{L}(i)}{V(i)}\right]^{*}
$$

where $I_{L}(i), P_{L}(i)$ and $V(i)$ are current, apparent power and voltage of the load at node $i$.

- The current of the last branch is the current of the last node. So starting from the last node to the first one by using Kirchhoff's current law (KCL) (backward sweep), the current of the network branches $J_{1 \times N b r}$ are calculated.

- Voltage drop of the network is calculated by the following equation $V_{d}=Z J$. Where $\mathrm{Z}$ is the impedance, $d \in[1, N b r]$ and $V_{d}$ is voltage drop of each branch.

- Since the voltage of reference node is taken as 1 or $1.05 \mathrm{pu}$. The voltage of next node is calculated by subtracting the corresponding voltage drop from the voltage of previous node (forward sweep) and $V_{k}$ will be updated.

- The procedure from step 2 is repeated until convergence criteria are satisfied. The convergence criteria is

$$
\Delta V_{k}=V_{k}(i t r)-V_{k}(i t r-1)<\varepsilon
$$

where $i t r$ is number of iteration and $\varepsilon$ is the threshold.

\section{Bacterial-Foraging Optimization Algorithm}

Inspiration from the natural creatures and nature has been taken from many years to solve the complex real world problems, and the algorithm which are inspired from the natural biological behaviour are called Biological Inspired Algorithms (BIA). The BIA inspired from the foraging behaviour of bacteria (E.coli) is called Bacterial Foraging Optimization Algorithm (BFOA), proposed by Passino ([23]; [24]). Since its inception BFOA has been widely accepted as global optimization algorithm for real world problems such as transmission loss reduction [25], learning of artificial neural networks [26], active power filters [27], optimal controller design ([23]), and harmonic estimation [28]. Foraging is a process of moving the bacteria towards more nutrients region through neutral medium, and avoiding the poisonous substances. The main steps of BFOA are as follows ([29]): 
Step 4.1) Initialize the problem and algorithm parameters

Step 4.2) Chemotaxis

Step 4.3) Reproduction

Step 4.4) Elimination-dispersion

These steps are described in the following sections:

\subsection{Initialize the problem and algorithm parameters}

Initialize the positions of ' $\mathrm{N}$ ' (say) number of bacteria. Let it be $\mathrm{X}^{1}, \mathrm{X}^{2}, \mathrm{X}^{3}, \ldots \mathrm{X}^{\mathrm{N}}$ corresponding to ' $\mathrm{N}$ ' bacterium $b^{1}, b^{2}, b^{3}, \ldots b^{N}$. The position vector $X^{1}, X^{2}, X^{3}, \ldots X^{N}$ is the initial population for the optimization problem, specified as follows:

Minimize $f(s)$

Subject to $s_{\mathrm{k}} \in Y_{k}, k=1,2,3, \ldots M$

Where $f(s)$ is the objective function, $s$ is the control variable which is set of all decision variable $s_{k}$ and $M$ is number of decision variables, $Y_{k}$ is the set of all possible range of values corresponding to the decision variable $s_{k}$. The initial position of the bacteria is initialized randomly with the array of open switches as $X$

$$
X=\left[\begin{array}{c}
X^{1} \\
X^{2} \\
X^{3} \\
\cdot \\
\cdot \\
\cdot \\
X^{N-1} \\
X^{N}
\end{array}\right]=\left[\begin{array}{cccccc}
x_{1}^{1} & x_{1}^{2} & x_{1}^{3} & x_{1}^{M-1} & x_{1}^{M} \\
x_{2}^{1} & x_{2}^{2} & x_{2}^{3} & \ldots & x_{2}^{M-1} & x_{2}^{M} \\
x_{3}^{1} & x_{3}^{2} & x_{3}^{3} & \ldots & x_{3}^{M-1} & x_{3}^{M} \\
\cdot & \cdot & \cdot & \cdot & \cdot & \cdot \\
\cdot & \cdot & \cdot & \cdot & \cdot & \cdot \\
\cdot & \cdot & \cdot & \cdot & \cdot & \cdot \\
x_{N-1}^{1} & x_{N-1}^{2} & x_{N-1}^{3} & \ldots & x_{N-1}^{M-1} & x_{N-1}^{M} \\
x_{N}^{1} & x_{N}^{2} & x_{N}^{3} & & x_{N}^{M-1} & x_{N}^{M}
\end{array}\right]
$$

The other parameters required for BFOA is also specified in this step. These are Number of bacteria $(\mathrm{N})$, Chemotactic step size(c), Swimming length (Ns), Elimination/dispersal probability $\left(\mathrm{P}_{\mathrm{ed}}\right)$, Attractant factor (A), and Repellent Factor (R).

\subsection{Chemotaxis}

It is the tendency of the bacteria to move towards the sources of Nutrients. It consists of two stages which are as following:

\section{(a) Tumbling:}

It is the tendency of the bacteria to change their positions in search of Nutrients. Let $X_{\text {new }}^{i}$ be the next position of the $\mathrm{i}^{\text {th }}$ bacteria whose current position is $X^{i}$. They are related as described below.

$$
X_{\text {new }}^{i}=X^{i}+\mathrm{c} \varphi
$$

Where 


$$
\varphi=\frac{\Delta}{\sqrt{\Delta^{T}} \Delta} \Delta \epsilon \mathrm{R}^{\mathrm{m}}
$$

such that each element of the vector $\Delta$ is in the range [-1 1]. $\varphi$ is the unit walk in random direction. ' $c$ ' is called as chemotactic step size. The new positions are computed for $i=1,2, \ldots \mathrm{N}$.

\section{(b) Swimming:}

Bacterium will tend to keep on moving in the particular direction if it is in the direction that is rich in nutrients.

Mathematically if $f\left(X_{\text {new }}^{i}\right)<f\left(X^{i}\right)$, then another swimming in the same direction $(\varphi)$ is taken by the $\mathrm{i}^{\text {th }}$ bacteria and it can be continued up to $N_{s}$ steps. After the completion of $N_{s}$ steps bacteria goes to the step 4.3. If $f\left(X_{n e w}^{i}\right)$ $\geq f\left(X^{i}\right)$, bacteria comes out of the tumbling stage and goes to the step 4.3.

$f\left(X^{i}\right)<0$ can be treated as the presence of nutrients, $f\left(X^{i}\right)=0$ can be treated as neutral while $f\left(X^{i}\right)>0$ can be treated as presence of toxic substances. In nature there is the social communication between bacterium such that they are neither close together nor far away from each other. This is done by releasing the chemical by the bacteria. The chemical signal can be either attractant or Repellent. If the chemical signal released by the particular bacteria is attractant in nature, then it attracts other bacteria to come to its position. On the contrary if the chemical signal released by the particular bacteria is repellent in nature, it doesn't allow other bacteria to come to its position.

The social communication between bacterium can be simulated using the modified objective function to be computed for the $\mathrm{i}^{\text {th }}$ position corresponding to the $\mathrm{i}^{\text {th }}$ position bacteria as given below.

$$
f \bmod \left(X^{i}\right)=f\left(X^{i}\right)+f \operatorname{social}\left(X^{i}\right)
$$

where fmod is the modified objective function computed for the $\mathrm{i}^{\text {th }}$ position $X^{i}$ corresponding to the $\mathrm{i}^{\text {th }}$ bacteria. $f\left(X^{i}\right)$ is the actual objective function value computed for the $\mathrm{i}^{\text {th }}$ position $X^{i}$ corresponding to the $\mathrm{i}^{\text {th }}$ bacteria. $f \operatorname{social}\left(X^{i}\right)$ is the attractant cum repellent signal computed for the $\mathrm{i}^{\text {th }}$ position $X^{i}$ corresponding to the $\mathrm{i}^{\text {th }}$ bacteria as displayed below.

$$
\begin{aligned}
& \text { Let } d_{i j}=\left\|X^{i}-X^{j}\right\|^{2} \\
& \operatorname{fsocial}\left(X^{i}\right)=\mathrm{m}\left(\sum_{j=1}^{N} e^{-R d_{i j}}-\sum_{j=1}^{N} e^{-A d_{i j}}\right)
\end{aligned}
$$

Note that if the first term $\sum_{j=1}^{N} e^{-R d_{i j}}$ is reduced if distance between the $\mathrm{i}^{\text {th }}$ position and others are made large and hence it acts as the repellent signal. Similarly the second term $-\sum_{j=1}^{N} e^{-A d_{i j}}$ is reduced if the distance between the $\mathrm{i}^{\mathrm{th}}$ position and others are made small and hence it acts as the attractant signal. ' $\mathrm{R}$ ' is the repellent factor and ' $\mathrm{A}$ ' is the attractant factor.

\subsection{Reproduction}

After step 4.2, best ' $\mathrm{N} / 2$ ' $(50 \%)$ bacteria measured in terms of its health are survived. The survived bacterium are subjected to reproduction to obtain ' $N$ ' bacterium as described below.

Health of the bacteria is measured in terms of $f(X)$. If the functional value $f(X)$ is less, then the corresponding bacteria is healthier. Compute $f\left(X^{i}\right)$ for $\mathrm{i}=1,2,3, \ldots \mathrm{N}$ and arrange them in ascending order. First ' $\mathrm{N} / 2$ ' bacterium and the corresponding positions are selected. Let the positions be $\left[P^{l}, P^{2}, P^{3}, \ldots P^{N / 2}\right]$. Every bacteria is split 
into two bacterium and are placed in the same positions. Thus new set of positions corresponding to ' $N$ ' bacterium are given as $\left[P^{I}, P^{I}, P^{2}, P^{2}, P^{3}, P^{3}, \ldots P^{N / 2}, P^{N / 2}\right]=\left[Q^{I}, Q^{2}, Q^{3}, \ldots Q^{N}\right]$ (say). Go to step 4.2. Repeat 4.2 and 4.3 for finite number of iterations. Then Go to step 4.4.

\subsection{Elimination-dispersion}

In real world process, some of the bacterium (i.e.) with probability 'Pd' are dispersed to new locations. This is achieved as follows.

Generate the random vector of size $1 \mathrm{xN}$. Sort the elements of the vector in an ascending order. Find the index corresponding to the first NxPd sorted numbers. Choose the positions of the bacterium corresponding to the obtained index. They are replaced as per the randomly generated positions on the optimization domain. The positions thus obtained are treated as the current best positions. Go to step 4.2. Repeat the steps 4.2-4.4 for the finite number of iterations. The best value in each iteration can also be tracked and the best among them can be declared as the optimal solution.

\section{Implementation of Bacterial-Foraging Optimization Algorithm in distribution network reconfiguration}

Objective function value must be minimum in order to achieve the best switching combination. The efficiency and reliability of distribution network can only be achieve by limiting the switching operations, because increasing the number of switching operations increases load flow studies, and thus becomes extremely inefficient not only from computational point of view, but it also becomes impractical as a real-time feeder reconfiguration strategy [16]. Conventional optimization methods becomes inefficient and impractical due to large search space. In order to limit the search space, all possible radial structure of the network (which meets all operating constraints) are generated and subsequently objective function are evaluated [30]. GIS is used in this paper for easy analysis, planning, and for obtaining all possible radial structures of the distribution network. Fig 1 and Fig 2 shows the 33-bus radial distribution network before and after the reconfiguration. One switch from every loop (Loop 1 to Loop 5) as shown in Fig 1 and Fig 2 must be open to maintain the radiality of the network. The open switches vectors from Fig 1 and Fig 2 keeps the network radial without violating the operating constraints. The open switches vectors of Fig 1 and Fig 2 are as follows:

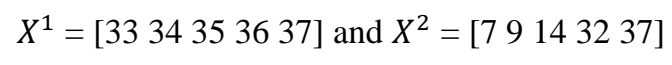

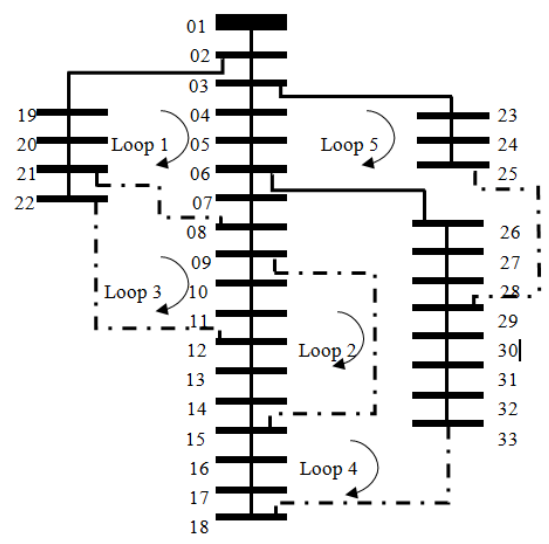

Fig.1. A 33-bus Radial Distribution Network Before Reconfiguration 


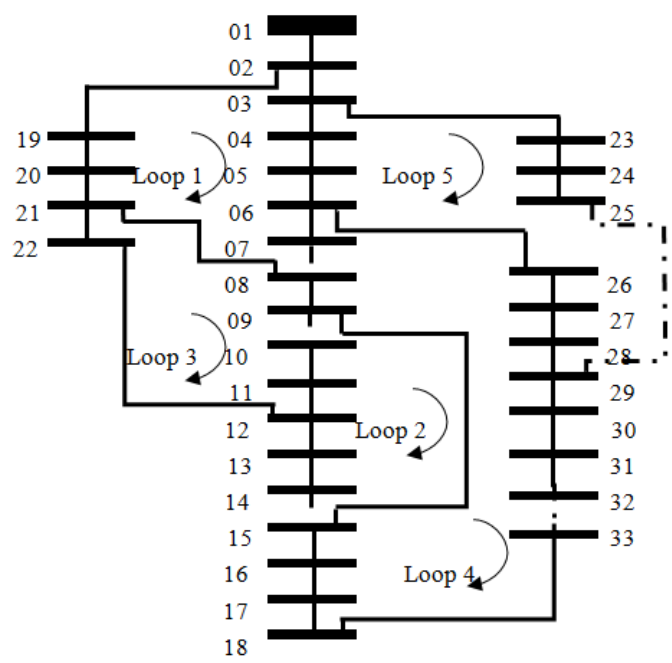

Fig.2. A 33-bus Radial Distribution Network After Reconfiguration

Similarly other possible radial network are generated without violating the operating constraints using GIS. GIS based distribution network is shown in the Fig 3 .

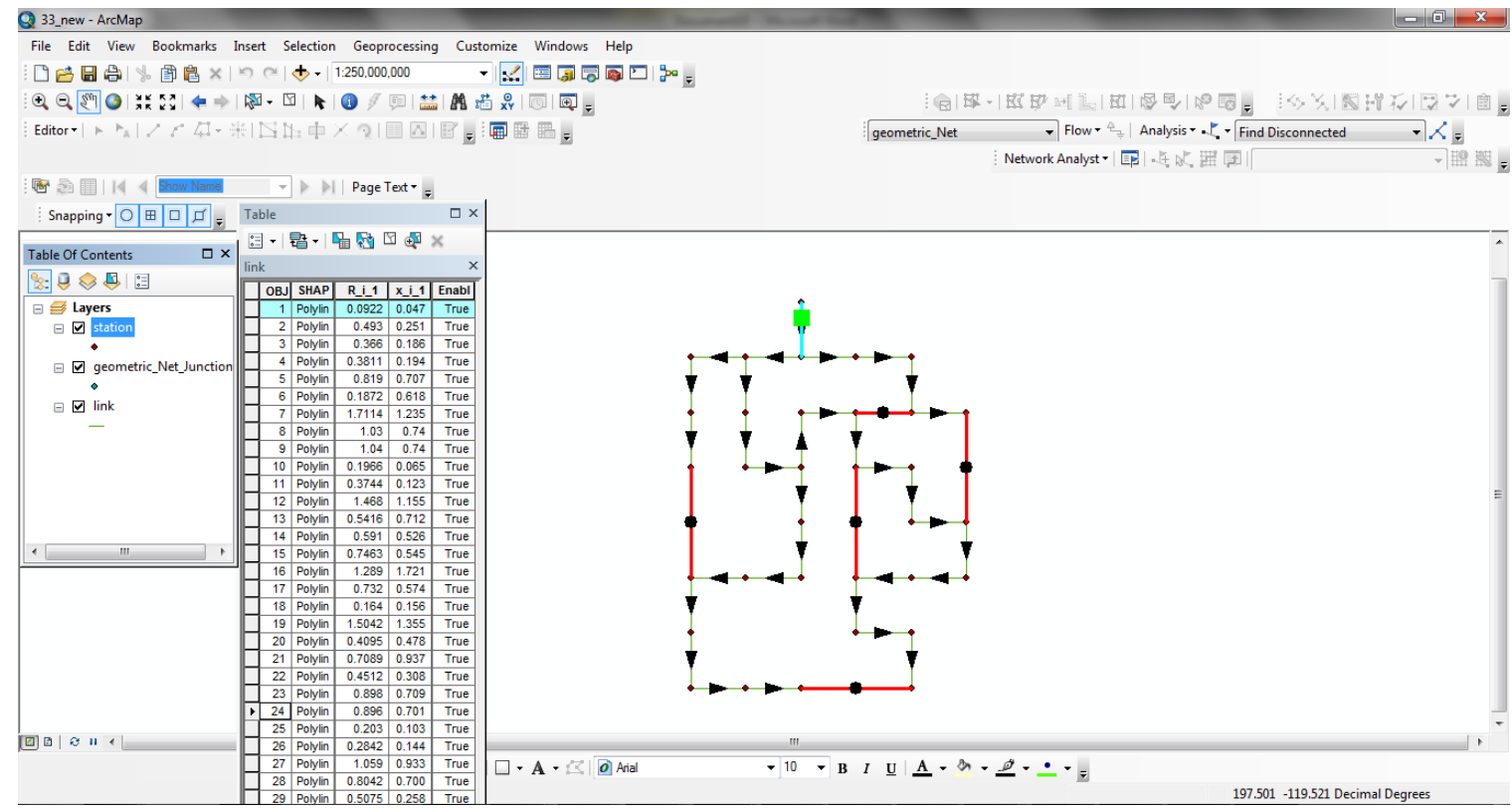

Fig.3. GIS Based Distribution Network

The initial positions of the bacteria is populated randomly with open switches vectors for $\mathrm{N}(20)$ number of bacteria as shown below: 


$$
X=\left[\begin{array}{l}
X^{1} \\
X^{2} \\
X^{3} \\
X^{4} \\
X^{5} \\
X^{6} \\
X^{7} \\
X^{8} \\
X^{9} \\
X^{10} \\
X^{11} \\
X^{12} \\
X^{13} \\
X^{14} \\
X^{15} \\
X^{16} \\
X^{17} \\
X^{18} \\
X^{19} \\
X^{20}
\end{array}\right]=\left[\begin{array}{ccccc}
7 & 9 & 14 & 24 & 30 \\
7 & 13 & 30 & 35 & 37 \\
10 & 14 & 17 & 20 & 27 \\
6 & 13 & 16 & 35 & 37 \\
4 & 10 & 17 & 21 & 24 \\
7 & 9 & 14 & 32 & 33 \\
8 & 12 & 29 & 33 & 37 \\
2 & 8 & 10 & 25 & 36 \\
7 & 11 & 26 & 34 & 36 \\
11 & 14 & 16 & 19 & 26 \\
7 & 9 & 21 & 25 & 36 \\
8 & 14 & 28 & 32 & 33 \\
33 & 34 & 35 & 36 & 37 \\
9 & 13 & 21 & 24 & 30 \\
3 & 10 & 13 & 26 & 34 \\
9 & 12 & 16 & 19 & 24 \\
5 & 10 & 17 & 23 & 27 \\
11 & 14 & 18 & 28 & 36 \\
16 & 19 & 21 & 26 & 34 \\
7 & 10 & 14 & 28 & 32
\end{array}\right]
$$

The updated positions of the bacteria will be obtained from the chemotaxis step given in 4.2 for the chemotactic step size c (1). If objective function value at updated position for $i^{\text {th }}$ bacteria is less than the objective function value at previous position for the same bacteria, then bacteria will keep on updating their position with same value of $\varphi$ up to Ns (5) steps. After this step the bacteria is arranged with the sorted objective function values in ascending order. First half (N/2 or 50\%) of the bacteria will survive and these bacterium reproduce to obtain $\mathrm{N}(100 \%)$ bacterium as discussed in section 4.3 . While in the last step, $\mathrm{N} * \mathrm{Pd}$ number of bacteria will be dispersed and these blanked spaces will be filled with the randomly generated open switches vectors, where $\mathrm{Pd}(0.75)$ is the probability of dispersion. This procedure is repeated until the termination criteria is satisfied. Both the attractant and repellent factor is taken as 2 in this simulation.

\section{Results and Discussion}

The proposed optimization method is tested on 33-bus radial distribution network. Simulation has been performed in MATLAB and ArcGIS. The distribution network consists of 33-buses, five normally open tie switches and 32 normally closed sectionalizing switches. The normally open tie switches are 33-37, and the normally closed sectionalizing switches are 1-32. The line and load data is given in Table 2. The network base is $\mathrm{V}=12.66 \mathrm{kV}, \mathrm{S}=10 \mathrm{MVA}$ and total real and reactive power loads on the system are $3715 \mathrm{~kW}$ and $2300 \mathrm{kVAr}$. The minimum bus voltage is 0.9134 p.u at bus 18 and have initial power loss of the system is $202.7 \mathrm{~kW}$. Distribution network before reconfiguration is shown in Fig 1.

After reconfiguration the open switches vector obtained by the proposed algorithm is 7, 9, 14, 32, and 37 . The minimum bus voltage is $0.9406 \mathrm{p}$.u at bus 32 and have real power loss of the configured network is 135.67 $\mathrm{kW}$. After reconfiguration overall $33.07 \%$ reduction in power loss and $2.89 \%$ improvement in minimum voltage are achieved as compared to the original configuration. Distribution network after reconfiguration is shown in Fig 2.The voltage and angle at each bus before and after reconfiguration is shown in Table 1.

Fig 4 shows the voltages angles while Fig 5 shows the voltages profiles at different buses before and after reconfiguration in 33-bus radial distribution network. In Fig 6 power loss before and after reconfiguration is 
shown. Even after the transfer of loads from one branch to another the power losses reduced at every branch after the reconfiguration. These improvement in power losses reduction after reconfiguration is clear indication of load balancing.

The proposed method is compared with the method proposed by Shirmohammadi and Hong [13], Zhu et. al [15] and Rao et. al [28]. The comparison table is shown in Table 3 and the convergence graph is shown in Fig 7.

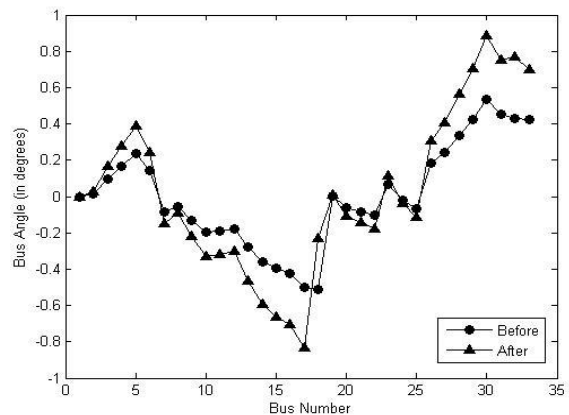

Fig.4. Voltages Angles at Different Buses Before and After Reconfiguration in 33-bus Radial Distribution Network

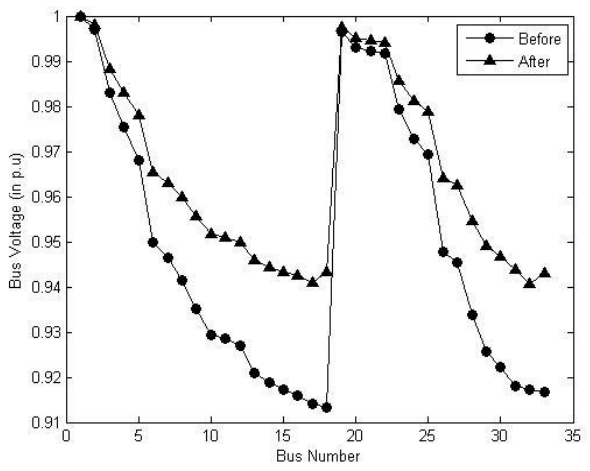

Fig.5. Voltage Profile of the 33-Radial Distribution Network Before and After Reconfiguration

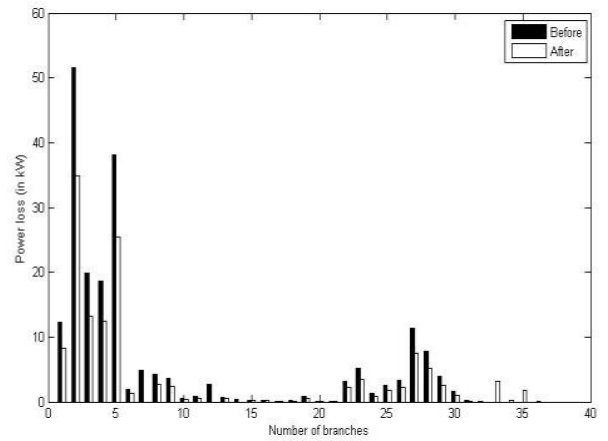

Fig.6. Power Losses at Every Branch in 33-Bus Radial Distribution Network Before and After Reconfiguration 


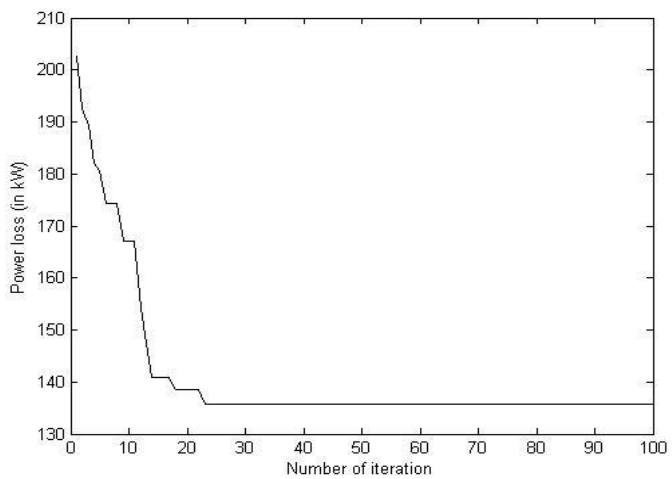

Fig.7. Convergence Characteristics of BFOA for 33-Bus Radial Distribution Network

Table 1. Voltage Profile and Voltages Angles Before and After Reconfiguration in 33-bus Radial Distribution Network

\begin{tabular}{|c|c|c|c|c|}
\hline \multirow[b]{2}{*}{ Bus No. } & \multicolumn{2}{|c|}{ Before Reconfiguration } & \multicolumn{2}{|c|}{ After Reconfiguration } \\
\hline & Voltage & Angle & Voltage & Angle \\
\hline 1 & & & & \\
\hline 2 & 1.0000 & 0 & 1.0000 & 0 \\
\hline 3 & 0.9970 & 0.0148 & 0.9980 & 0.0249 \\
\hline 4 & 0.9830 & 0.0985 & 0.9883 & 0.1651 \\
\hline 5 & 0.9755 & 0.1658 & 0.9831 & 0.2777 \\
\hline 6 & 0.9682 & 0.2341 & 0.9781 & 0.3917 \\
\hline 7 & 0.9498 & 0.1446 & 0.9655 & 0.2401 \\
\hline 8 & 0.9463 & -0.0872 & 0.9631 & -0.1479 \\
\hline $\begin{array}{l}0 \\
9\end{array}$ & 0.9415 & -0.0539 & 0.9598 & -0.0917 \\
\hline 10 & 0.9352 & -0.1312 & 0.9555 & -0.2203 \\
\hline 11 & 0.9294 & -0.1980 & 0.9516 & -0.3310 \\
\hline $\begin{array}{l}11 \\
12\end{array}$ & 0.9286 & -0.1914 & 0.9510 & -0.3199 \\
\hline $\begin{array}{l}12 \\
13\end{array}$ & 0.9271 & -0.1812 & 0.9500 & -0.3025 \\
\hline & 0.9210 & -0.2778 & 0.9458 & -0.4625 \\
\hline $\begin{array}{l}14 \\
15\end{array}$ & 0.9187 & -0.3585 & 0.9443 & -0.5964 \\
\hline & 0.9173 & -0.3976 & 0.9433 & -0.6612 \\
\hline $\begin{array}{l}16 \\
17\end{array}$ & 0.9160 & -0.4223 & 0.9424 & -0.7019 \\
\hline $\begin{array}{l}17 \\
18\end{array}$ & 0.9140 & -0.5017 & 0.9410 & -0.8335 \\
\hline & 0.9134 & -0.5120 & 0.9432 & -0.2308 \\
\hline 20 & 0.9965 & 0.0039 & 0.9976 & 0.0064 \\
\hline 21 & 0.9929 & -0.0636 & 0.9951 & -0.1083 \\
\hline & 0.9922 & -0.0831 & 0.9946 & -0.1414 \\
\hline $\begin{array}{l}22 \\
23\end{array}$ & 0.9916 & -0.1036 & 0.9941 & -0.1762 \\
\hline $\begin{array}{l}23 \\
24\end{array}$ & 0.9794 & 0.0673 & 0.9858 & 0.1123 \\
\hline $\begin{array}{l}24 \\
25\end{array}$ & 0.9727 & -0.0220 & 0.9811 & -0.0387 \\
\hline $\begin{array}{l}25 \\
26\end{array}$ & 0.9694 & -0.0662 & 0.9788 & -0.1132 \\
\hline $\begin{array}{l}26 \\
27\end{array}$ & 0.9479 & 0.1858 & 0.9642 & 0.3087 \\
\hline $\begin{array}{l}27 \\
28\end{array}$ & 0.9453 & 0.2443 & 0.9625 & 0.4061 \\
\hline $\begin{array}{l}28 \\
29\end{array}$ & 0.9339 & 0.3386 & 0.9547 & 0.5614 \\
\hline 29 & 0.9257 & 0.4249 & 0.9491 & 0.7036 \\
\hline 30 & 0.9222 & 0.5338 & 0.9466 & 0.8843 \\
\hline 31 & 0.9180 & 0.4534 & 0.9438 & 0.7495 \\
\hline 32 & 0.9171 & 0.4312 & 0.9406 & 0.7696 \\
\hline 33 & 0.9168 & 0.4237 & 0.9430 & 0.6999 \\
\hline
\end{tabular}


Table 2. Network Data for 33 bus System

\begin{tabular}{|c|c|c|c|c|c|c|}
\hline S.No. & From bus & To bus & $\mathrm{R}(\Omega)$ & $\mathrm{X}(\Omega)$ & $\begin{array}{l}\text { Real } \\
\text { Power }(\mathrm{kW})\end{array}$ & $\begin{array}{l}\text { Reactive } \\
\text { Power (kVAr) }\end{array}$ \\
\hline 1 & 1 & 2 & 0.0922 & 0.0470 & 100.0 & 60.0 \\
\hline 2 & 2 & 3 & 0.4930 & 0.2511 & 90.0 & 40.0 \\
\hline 3 & 3 & 4 & 0.3660 & 0.1864 & 120.0 & 80.0 \\
\hline 4 & 4 & 5 & 0.3811 & 0.1941 & 160.0 & 30.0 \\
\hline 5 & 5 & 6 & 0.8190 & 0.7070 & 60.0 & 20.0 \\
\hline 6 & 6 & 7 & 0.1872 & 0.6188 & 200.0 & 100.0 \\
\hline 7 & 7 & 8 & 0.7114 & 0.2351 & 200.0 & 100.0 \\
\hline 8 & 8 & 9 & 1.0300 & 0.7200 & 60.0 & 20.0 \\
\hline 9 & 9 & 10 & 1.0440 & 0.7400 & 60.0 & 20.0 \\
\hline 10 & 10 & 11 & 0.1966 & 0.0650 & 45.0 & 30.0 \\
\hline 11 & 11 & 12 & 0.3744 & 0.1238 & 60.0 & 35.0 \\
\hline 12 & 12 & 13 & 1.4680 & 1.1550 & 60.0 & 35.0 \\
\hline 13 & 13 & 14 & 0.5416 & 0.7129 & 120.0 & 80.0 \\
\hline 14 & 14 & 15 & 0.5910 & 0.5260 & 60.0 & 10.0 \\
\hline 15 & 15 & 16 & 0.7463 & 0.5450 & 60.0 & 20.0 \\
\hline 16 & 16 & 17 & 1.2890 & 1.7210 & 60.0 & 20.0 \\
\hline 17 & 17 & 18 & 0.7320 & 0.5740 & 90.0 & 40.0 \\
\hline 18 & 18 & 19 & 0.1640 & 0.1565 & 90.0 & 40.0 \\
\hline 19 & 19 & 20 & 1.5042 & 1.3554 & 90.0 & 40.0 \\
\hline 20 & 20 & 21 & 0.4095 & 0.4784 & 90.0 & 40.0 \\
\hline 21 & 21 & 22 & 0.7089 & 0.9373 & 90.0 & 40.0 \\
\hline 22 & 3 & 23 & 0.4512 & 0.3083 & 90.0 & 50.0 \\
\hline 23 & 23 & 24 & 0.8980 & 0.7091 & 420.0 & 200.0 \\
\hline 24 & 24 & 25 & 0.8960 & 0.7011 & 420.0 & 200.0 \\
\hline 25 & 6 & 26 & 0.2030 & 0.1034 & 60.0 & 25.0 \\
\hline 26 & 26 & 27 & 0.2842 & 0.1447 & 60.0 & 25.0 \\
\hline 27 & 27 & 28 & 1.0590 & 0.9337 & 60.0 & 20.0 \\
\hline 28 & 28 & 29 & 0.8042 & 0.7006 & 120.0 & 70.0 \\
\hline 29 & 29 & 30 & 0.5975 & 0.2585 & 200.0 & 600.0 \\
\hline 30 & 30 & 31 & 0.9744 & 0.9630 & 150.0 & 70.0 \\
\hline 31 & 31 & 32 & 0.3105 & 0.3619 & 210.0 & 100.0 \\
\hline 32 & 32 & 32 & 0.3410 & 0.5302 & 60.0 & 40.0 \\
\hline 33 & 21 & 8 & 2.0000 & 2.0000 & ----- & ----- \\
\hline 34 & 9 & 15 & 2.0000 & 2.0000 & ----- & ----- \\
\hline 35 & 12 & 22 & 2.0000 & 2.0000 & ---- & ----- \\
\hline 36 & 18 & 33 & 0.5000 & 0.5000 & ----- & ----- \\
\hline 37 & 25 & 29 & 0.5000 & 0.5000 & ----- & ----- \\
\hline
\end{tabular}

Table 3. Comparison Table of 33-bus Radial Distribution Network

\begin{tabular}{|llcc|}
\hline Methods & Open switches & Power loss $(\mathrm{kW})$ & Percentage of loss reduction \\
\hline Proposed BFOA & $7,9,14,32,37$ & 135.67 & $33.07 \%$ \\
Rao et. al (Harmony Search Algorithm) [28] & $7,10,14,36,37$ & 138.06 & $31.89 \%$ \\
Zhu et. al (Refined Genetic Algorithm) [15] & $7,9,14,32,37$ & 139.53 & $31.16 \%$ \\
\hline Shirmohammadi and Hong [13] & $7,10,14,33,37$ & 141.54 & $30.17 \%$ \\
\hline
\end{tabular}




\section{Conclusions}

In this paper BFOA is proposed along with BFS and GIS to minimize the real power loss through reconfiguration and improving the voltage profile of the distribution network. The simulation is performed on IEEE 33-bus radial distribution network and results are compared with the other methods proposed by Rao et. $a l$, Zhu et. al, and Shirmohammadi and Hong. It can be shown from the table that the loss reduction achieved by BFOA is approx. 2-3\% more than the existing approach and having good convergence characteristic. Power loss reduction at every branch is shown in Fig 6 and is clear indication of load balancing. After reconfiguration $2.89 \%$ improvement in voltage profile can also be seen from the Table 1 . The efficiency and good convergence characteristic of the proposed approach proves that it can be used in large-scale network.

\section{References}

[1] Augugliaro A, Dusonchet L, Ippolito M, Sanseverino E R. Minimum losses reconfiguration of MV distribution networks through local control of tie-switches. IEEE Trans. Power Del. 2003:18(3): 762-771.

[2] Kim H, Ko Y. Artificial neural network based feeder reconfiguration for loss reduction in distribution systems. IEEE Trans. Power Del. 1993:8(3): 1356-1367.

[3] Chiou J P, Wang F S. Hybrid method of evolutionary algorithms for static and dynamic optimization problems with application to fed-batch fermentation process. Comput. Chem. Eng. 1999:23: 1277-1291.

[4] Chiou J, Chang C. Variable scaling hybrid differential evaluation for solving network reconfiguration of distribution system. IEEE Trans. Power Syst. 2005:20(2): 668-674.

[5] Delbem A, Carvalho A, Bretas N. Main chain representation for evolutionary algorithms applied to distribution system reconfiguration. IEEE Trans. Power Syst. 2005:20(1): 425-436.

[6] Gomes V, Carneiro S. A new reconfiguration algorithm for large distribution systems. IEEE Trans. Power Del. 2005:20(3): 1373-1378.

[7] Taher N, Reza K, Bahman B F. A hybrid evolutionary algorithm for distribution feeder reconfiguration. Sadhana 2010:35(2):139-162.

[8] Mostafa S, Marzieh D, Mohammad S, Hadi H K. Optimal reconfiguration and capacitor placement for power loss reduction of distribution system using improved binary particle swarm optimization. Int. J. Energy Environ Eng. 2014:5:73.

[9] W.M. Ritchie, P.W. Beard, A. Barker, D.G.T. Lewis. Loss Reduction - an overview of the problems and solutions. Power Technol Int. 1988:191-194.

[10] Civanlar S., Grainger J.J., Yin H., Lee S.S.H. Distribution feeder reconfiguration for loss reduction. IEEE Trans. on Power Del. 1988:3(3):1217-1223.

[11] Dolatdar E, Soleymani S, Mozafari B. A new distribution network reconfiguration approach using a tree model. World Academy of Science, Engineering and Technology 2009:58:1186-1193.

[12] Boor Z, Hosseini S M. GA based optimal placement of DGs for loss reduction and reliability improvement in distribution networks with time varying loads. I.J. Intelligent Systems and Applications 2013:04:55-63.

[13] Merlin A, Back H. Search for a minimal-loss operating spanning tree configuration in an urban power distribution system. In Proc. $5^{\text {th }}$ Power System computation Conf. (PSCC), Cambridge, U.K 1975:1-18.

[14] Shirmohammadi D, Hong H W. Reconfiguration of electric distribution networks for resistive line losses reduction. IEEE Trans. on Power Del. 1989:4(2):1492-1498.

[15] Nara K, Shiose A, Kitagawoa M, Ishihara T. Implementation of genetic algorithm for distribution systems loss minimum reconfiguration. IEEE Trans. Power Syst. 1992:7(3):1044-1051.

[16] Zhu J Z. Optimal reconfiguration of electrical distribution network using the refined genetic algorithm. 
Elect. Power Syst. Res. 2002:62:37-42.

[17] Chiang H D, Rene J J. Optimal network reconfiguration in distribution systems: Part 1: A new formulation and a solution methodology. IEEE Trans. Power Del. 1990:5(4):1902-1908.

[18] Cheng H C, Kou C C. Network reconfiguration in distribution systems using simulated annealing. Elect. Power Syst. Res. 1994:29:227-238.

[19] Das D. A fuzzy multiobjective approach for network reconfiguration of distribution systems. IEEE Trans. Power Del. 2006:21(1):202-209.

[20] Kumar K S, Jayabarathi T. Power system reconfiguration and loss minimization for an distribution systems using bacterial foraging optimization algorithm. Electrical Power and Energy Systems 2012:36:13-17.

[21] Afzalan M, Taghikhani M A. Placement and sizing of DG using PSO\&HBMO algorithm in radial distribution network. I.J. Intelligent Systems and Applications. 2012:10:43-49.

[22] Ehsan M, Javad R. A new method for load flow on radial distribution network. In $12^{\text {th }}$ Iranian Student Conference on Electrical Engineering (ISCEE) 2009.

[23] Passino K M. Biomimicry of bacterial foraging for distribution optimization and control. IEEE Control Syst. Mag. 2002:22(3):52-67.

[24] Liu Y, Passino K M. Biomimicry of social foraging bacteria for distribution optimization: Models, Principles, and emergent behaviors. J. Optimization Theory Appl. 2002:115(3):603-628.

[25] Tripathy M, Mishra S, Lai L L, Zhang Q P. Transmission loss reduction based on FACTS and bacteria foraging algorithm. In Proc. PPSN. 2006:222-231.

[26] Kim D H, Cho C H. Bacterial foraging based neural network fuzzy learning. In Proc. IICAI 2005:20302036.

[27] Mishra S, Bhende C N. Bacterial foraging technique-based optimized active power filter for load compensation. IEEE Trans. Power Del. 2007:22(1):457-465.

[28] Mishra S. A hybrid least square-fuzzy bacterial foraging strategy for harmonic estimation. IEEE Trans. Evol. Comput. 2005:9(1):61-73.

[29] Gopi E S. Mathematical summary for digital signal processing applications with matlab. Springer; 2010.

[30] Rao R S, Narasimham S V L, Raju M R, Rao A S. Optimal network reconfiguration of large scale distribution system using harmony search algorithm. IEEE Trans. On Power Syst. 2011:26(3):1080-1088.

\section{Authors' Profiles}

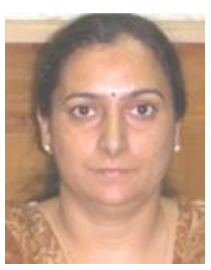

Manju Mam, Research Scholar, Manav Rachna is B.Tech. in Electronics and Communication Engineering from NIT, Srinagar and M.S in Software Systems from BITS Pilani. She also holds an MBA degree with specialization in HR. She has over 26 years of teaching experience. Her areas of interest are Power Distribution, Geographical Information Systems, IT in Power Industry

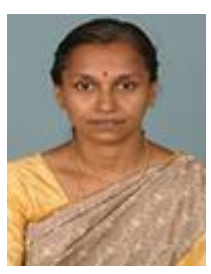

Dr. Leena G. has B.Tech in Electrical and Electronics Engg. and M.Tech in Control Systems from Kerala University in 1991 and 1995 respectively. She completed her PhD in 2007 from Indian Institute of Technology, Kharagpur, India. She had over 16 years of teaching experience and presently she is a Professor in the Electrical and Electronics Department of Manav Rachna International University, Faridabad, India. Her areas of interest are nonlinear system, decentralized control, sliding mode control, Power Distribution etc. 


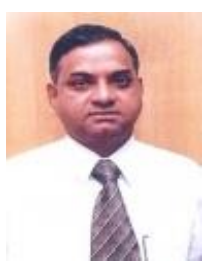

Dr. N.S. Saxena. Professor, Operations Management, MDI, graduated in Electrical Engineering from Madhav Engg. College. He completed Post Graduation in Power Systems and doctoral degree from IIT, Kanpur in 1983. He has over 38 years of work experience in different executive and managerial positions in various Academic Institutions and Central Sector Public Sector Utilities viz. NTPC Ltd. and PGCIL. He retired as Director General of NPTI and his last assignment before joining MDI was Adviser to Hythro Power Corporation Ltd.

How to cite this paper: Manju Mam, Leena G, N.S. Saxena,"Distribution Network Reconfiguration for Power Loss Minimization Using Bacterial Foraging Optimization Algorithm", International Journal of Engineering and Manufacturing(IJEM), Vol.6, No.2, pp.18-32, 2016.DOI: 10.5815/ijem.2016.02.03 